\title{
Whole Gut Motility Evaluation by Wireless Motility Capsule in a Patient with Parkinson's Disease
}

\author{
Chethan Ramprasad*, Baharak Moshiree \\ University of Miami Miller School of Medicine, Miami, Florida
}

Received: August 17, 2016; Accepted: August 31, 2016; Published: September 15, 2016

*Corresponding author: Chethan Ramprasad, 1550 Brickell Ave Apt B412, Miami, FL USA, Tel: (513) 532-4657; Email: c.ramprasad@med.miami.edu

\begin{abstract}
Parkinson's disease (PD) affects the nerves of the entire gastrointestinal (GI) tract and may result in profound gastrointestinal (GI) dysfunction leading to poor patient outcomes. Common GI disturbances in patients with Parkinson's include gastroparesis, constipation, and small intestinal bacterial overgrowth (SIBO) syndrome.

We report a case of a 76-year-old man with Parkinson's disease who presented with bloating, abdominal distension for 6 months despite treatment with prokinetics and laxatives. Hydrogen breath testing was done showing high methane levels at baseline and throughout the study, suggesting SIBO. Wireless motility capsule study was done to evaluate whole gut motility and showed normal gastric and small bowel transit. Colonic transit time could not be assessed as the capsule exited the rectum seven days after the study was completed and only with use of enemas. Normal motility indices were found in the colon. MRI defecography further demonstrated dilation of the rectum up to $9.8 \mathrm{~cm}$, consistent with megarectum. To evaluate potential causes of obstructive defecation versus neurological deficit, anorectal manometry with balloon expulsion testing was done and was also consistent with dyssynergic defecation-pelvic floor disorder causing constipation. Biofeedback therapy will be considered to alleviate the patient's symptoms. Dyssynergic defecation is a common gastrointestinal finding in Parkinson's disease and conservative measures such as biofeedback therapy should be used as a cornerstone for treatment rather than laxatives alone.
\end{abstract}

Keywords: Parkinson's; Wireless pill; Small intestinal bacterial overgrowth; Dyssynergic defecation

\section{Abbreviations}

PD: Parkinson's disease; GI: gastrointestinal; SIBO: small intestinal bacterial overgrowth syndrome Introduction

Parkinson's disease (PD) affects the nerves of the entire gastrointestinal (GI) tract and may result in profound gastrointestinal (GI) dysfunction leading to poor patient outcomes [1, 5]. GI dysfunction in PD has been reported as high as 77 to $81 \%[1,2]$. Patients often report that the onset of GI symptoms preceded Parkinsonian motor symptoms of tremor, stiffness, slowness, and shuffling, emphasizing the importance of early identification [3, 4]. GI dysfunction in patients with PD can be difficult to treat given patients underlying dysphagia with inability to swallow tablets, due to medication side effects including central nervous system effects and given the limited options of approved treatments [5]. In particular, presence of underlying gastroparesis- a delayed gastric emptying- and small intestinal bacterial overgrowth (SIBO) syndrome can further alter the function of medications used to treat PD. For example, gastroparesis can contribute to fluctuations in response to levodopa therapy [6]. Moreover, the only medication FDA approved for treatment of gastroparesis, metoclopramide, has an FDA mandated black box warning as they can cause tardive dyskinesia or worsen pre-existing PD [7]. We present here a complex case of a patient with several GI manifestations and describe the motility workup that lead to treatment of our patient.

\section{Case Presentation}

A 76-year-old patient with Parkinson's disease (PD) was referred to our tertiary motility clinic for further evaluation of bloating, constipation, and abdominal distension with discomfort. Symptoms of PD began at age of 71, manifested by neurocognitive disorder with an emphasis on visual spatial deficiencies. The patient presented with bloating for six months, only relieved by defecation. He denied nausea, vomiting, early satiety, gastroesophageal reflux, dysphagia, odynophagia, regurgitation, changes in appetite, GI bleeding, or weight loss. He had regular, soft bowel movements daily without tenesmus. Patient was taking donepezil, rasagiline, donepezil for Parkinson's, finasteride and tamsulosin for BPH, eye lubricants, calcium supplement gummies, Vitamin D3, and Coenzyme q10. He did not have any other known medical history and specifically no rectal or abdominal surgeries. He had a 30 pack year cigarette smoking history as well as heavy alcohol consumption of eight glasses of wine daily for more than ten years, which were both discontinued approximately five years prior to our examination. On physical examination, he had a body mass index of $25.77 \mathrm{Kg} /$ $\mathrm{m}^{2}$ (height $1.8 \mathrm{~m}$ and weight $86.2 \mathrm{~kg}$ ). Abdominal examination was unremarkable other than generalized fullness of abdomen with distension on visual inspection and tympanic to percussion. Digital rectal exam showed copious hard brown colored stool in 
the rectum, normal tone and no masses. The puborectalis muscle could not be palpated given large stool burden. Per history, a prior colonoscopy had been performed 3 years ago with normal results. Prior to presentation to our clinic, patient had been given domperidone to treat his abdominal bloating and discomfvort without relief. This was discontinued already given lack of benefit.

Given the absence of dysphagia despite having PD, a whole gut transit study was performed called the wireless motility capsule (SmartPill@) after ingestion of a bar meal [8]. This test is FDA approved for evaluation of both constipation thought to be slow transit and for gastroparesis. Findings showed a normal gastric transit of 3:18 hours without evidence of gastroparesis, normal small bowel transit of 3:58 hours without evidence of small bowel dysmotility (contractions/min: .4, mean amplitude: 49.43, motility index: 39.74). However, despite lack of history of constipation, colonictransit time was severely delayed as the capsule did not exit the rectum at the end of the study. The capsule should be passed within the 5 day test [8]. Four days after the 5 day testing, an abdominal film was obtained and the capsule was seen still present in the rectum (Figure 1). Another $\mathrm{x}$ ray subsequently showed the same (done 8 days after) therefore fleet enemas were given to confirm capsule exit. This finding of delayed colonic transit was read as most likely due to dyssynergia and obstructive defecation as the capsule was seen in the same location in the rectum and was not seen in other segments of the colon. Figure 2 demonstrates these findings as shown by SmartPill@ tracking.

Patient was also evaluated for bacterial overgrowth given main complaints of bloating but not constipation. A hydrogen breath test with $75 \mathrm{~g}$ of glucose in $150 \mathrm{ml}$ of water. Samples were analyzed in a Quintron Breath Tracker Microanalyzer. Results were abnormal and demonstrated high methane (CH4) levels at baseline 90ppm CH4 (normal <20ppm) and throughout study with peak methane levels seen at $15 \mathrm{~min}$ and $180 \mathrm{~min}$, both at 106ppm CH4 (normal <20ppm) (Figure 3).

MRI defecography was then performed to evaluate the rectal morphology and rule out prolapse and megarectum. This demonstrated rectal dilation to $9.8 \mathrm{~cm}$, consistent with megarectum. Anorectal manometry was then performed showing dyssynergic defecation and megarectum as well. External sphincter pressure was normal and patient had decreased sensation on rectal balloon distension.

Findings were concluded as severe defecatory dysfunction partially neurological and also due to pelvic floor disorder. For treatment of SIBO was treated with rifaximin 550mg TID for 14 days especially as methane-producing bacteria were implicated likely due to severe constipation even though patient did not complain of straining or hard stools and was having bowel movements daily. Patient was also started on probiotics (Lactobacillus rhamnosus and psyllium were started after glucose hydrogen breath test and wireless pill study for treatment of constipation. For treatment of dyssynergia patient was started on biofeedback therapy in combination with the Psyllium.

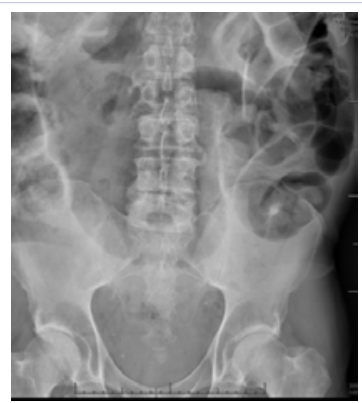

Figure 1: Colonic transit time was severely delayed as the capsule did not exit the rectum at the end of the 5 day study. Four days after the 5 day testing, an abdominal film was obtained and the capsule was seen still present in the rectum..

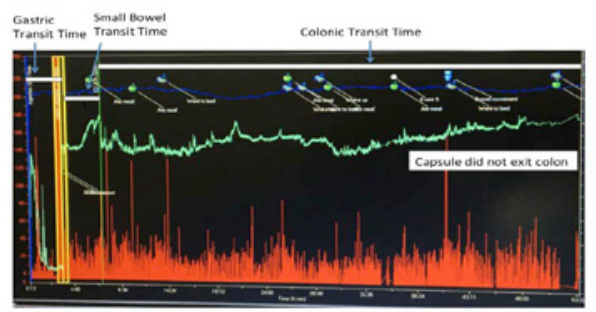

\begin{tabular}{|c|c|}
\hline & hr:min \\
\hline $\begin{array}{c}\text { Gastric emptying time } \\
>4 \mathrm{~h} \text { suggests delayed gastric emptying }\end{array}$ & 3.18 \\
\hline $\begin{array}{c}\text { Small bowel transit time } \\
\text { Normal range is 2.5 to 6h }\end{array}$ & $3: 58$ \\
\hline $\begin{array}{c}\text { Colonic transit time } \\
>59 \mathrm{~h} \text { indicates delayed colonic transit }\end{array}$ & $47: 00$ \\
\hline $\begin{array}{c}\text { Small/large bowel transit time } \\
>65 \mathrm{~h} \text { indicates delayed SLBTT }\end{array}$ & $50: 59$ \\
\hline $\begin{array}{c}\text { Whole gut transit time } \\
\text { Normal is < } 73 \mathrm{~h}\end{array}$ & 54.18 \\
Contractions/min: .4, mean amplitude: 49.43, motility index: 39.74
\end{tabular}

Figure 2: Wireless motility capsule study showing normal stomach and small bowel contractions but no capsule exit at end of study (see arrow).

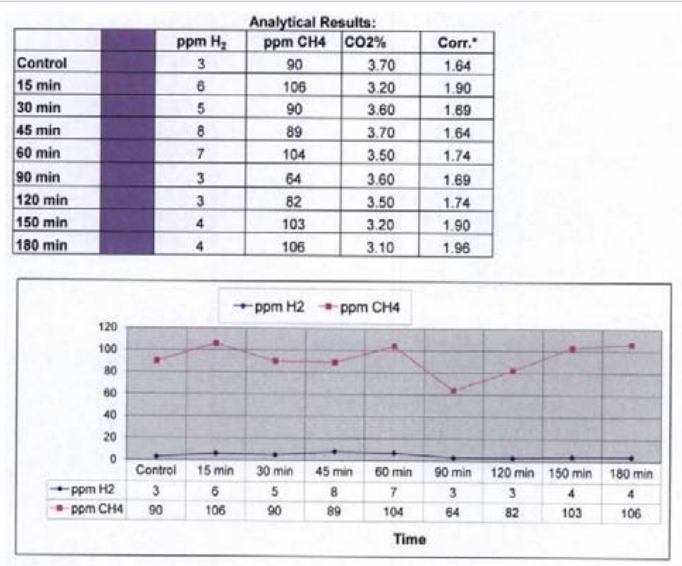

Figure 3: Hydrogen breath test results. High methane (CH4) levels were seen at baseline 90ppm CH4 (normal <20ppm) and throughout study. Peak methane levels were seen at $15 \mathrm{~min}$ and then at $180 \mathrm{~min}$ at $106 \mathrm{ppm}$ CH4. 
Significant relief of his symptoms was noted after treatment with rifaximin.

\section{Discussion}

The clinical manifestations of Parkinson's disease are the result of nerve damage to the gastrointestinal (GI) tract and often lead to gastroparesis, constipation, or small intestinal bacterial overgrowth (SIBO) syndrome [5]. Our patient complained particularly of bloating and discomfort but did not describe constipation or other upper GI symptoms. His symptoms were largely due to development of small intestinal bacterial overgrowth (SIBO) which his likely secondary to his obstructive defecation as he did not have constipation. Symptoms of SIBO may include bloating, abdominal pain, weight loss, diarrhea, and occasionally constipation and abdominal distention [5]. SIBO can be diagnosed through endoscopic jejunal aspiration by identifying $>10^{5}$ colony forming units $/ \mathrm{ml}$ of organisms or breath testing with identification of hydrogen or methane producing bacteria [9]. Although the exact prevalence is not known for the general population, SIBO has been found to be more common in patients with PD as compared to controls using the glucose breath test, $54 \%$ of patients with PD and $8 \%$ of control (OR 2.24, CI: 3.5-48.24.) [10]. The finding of dyssynergic defecation and megarectum in this patient is likely both neurologic as sensation was diminished and likely behavioral as this is very common in the general population.

In patients with $\mathrm{PD}$, glucose hydrogen breath testing may be helpful to identify small intestinal bacterial overgrowth however as the testing has a high false positive rate, further physiologic testing of the whole gut with wireless motility capsule or anorectal testing with anorectal manometry may be warranted to best evaluate patients underlying cause. Wireless motility capsule has the advantage of limited radiation as well as the ability to assess under real-life physiologic condition unlike scintigraphy or colonic manometry [8]. Anorectal manometry is helpful in making a diagnosis of dyssynergia. Complete motility studies should be considered to rule out coexisting upper gastrointestinal motility disorders such as gastroparesisor causes of constipation if patient does not have dysphagia as wireless motility capsule study is contraindicated in that setting given risk of esophageal impaction. In the patient without dysphagia, the wireless motility capsule can identify both gastroparesisand slow transit constipation [8]. If anorectal dyssynergia is found, biofeedback therapy is to be regarded as the first choice treatment [11]. Biofeedback therapy is more effective than sham feedback, pelvic floor exercises, laxatives, and muscle relaxant drugs, both on short and long term basis without side effects $[14,15]$.

\section{Conflict of Interest}

Baharak Moshiree receives financial support from Prometheus Laboratory: grant support and advisory board, and Given Imaging: Speakers bureau and grant support. The other authors declare no conflict of interest

\section{References}

1. Khedr EM, El Fetoh NA, Khalifa H, Ahmed MA, El Beh KM. Prevalence of non motor features in a cohort of Parkinson's disease patients. Clinical neurology and neurosurgery. 2013;115(6):673-677. doi: 10.1016/j. clineuro.2012.07.032.

2. Martinez-Martin P. The importance of non-motor disturbances to quality of life in Parkinson's disease. Journal of the neurological sciences. 2011;310(1-2):12-16. doi: 10.1016/j.jns.2011.05.006.

3. Sung HY, ParkJW, Kim JS. The frequency and severity of gastrointestinal symptoms in patients with early Parkinson's disease. Journal of movement disorders. 2014;7(1):7-12. doi: 10.14802/jmd.14002.

4. Cersosimo MG, Raina GB, Pecci C, Pellene A, Calandra CR, Gutiérrez $C$, et al. Gastrointestinal manifestations in Parkinson's disease: prevalence and occurrence before motor symptoms. Journal of neurology. 2013;260(5):1332-1338.

5. Barboza JL, Okun MS, Moshiree B. The treatment of gastroparesis, constipation and small intestinal bacterial overgrowth syndrome in patients with Parkinson's disease. Expert opinion on pharmacotherapy. 2015;16(16):2449-2464. doi: 10.1517/14656566.2015.1086747.

6. Marrinan S, Emmanuel AV, Burn DJ. Delayed gastric emptying in Parkinson's disease. Movement Disorders. 2014;29(1):23-32. doi: 10.1002/mds.25708.

7. Avorn J, Gurwitz JH, Bohn RL, Mogun H, Monane M, Walker A. Increased incidence of levodopa therapy following metoclopramide use. JAMA. 1995;274(22):1780-1782.

8. Rao SS, Kuo B, McCallum RW, Chey WD, DiBaise JK, Hasler WL, et al. Investigation of colonic and whole-gut transit with wireless motility capsule and radiopaque markers in constipation. Clinical gastroenterology and hepatology. 2009;7(5):537-544.

9. Bouhnik Y, Alain S, Attar A, Flourié B, Raskine L, Sanson-Le Pors MJ, et al. Bacterial populations contaminating the upper gut in patients with small intestinal bacterial overgrowth syndrome. The American journal of gastroenterology. 1999;94(5):1327-1331.

10. Gabrielli M, Bonazzi P, Scarpellini E, Bendia E, Lauritano EC, Fasano $A$, et al. Prevalence of small intestinal bacterial overgrowth in Parkinson's disease. Movement Disorders. 2011;26(5):889-892.

11. Longstreth GF, Thompson WG, Chey WD, Houghton LA, Mearin F, Spiller RC. Functional bowel disorders. Gastroenterology. 2006;130(5):1480-1491.

12. Braak H, de Vos RA, Bohl J, Del Tredici K. Gastric $\alpha$-synuclein immunoreactive inclusions in Meissner's and Auerbach's plexuses in cases staged for Parkinson's disease-related brain pathology. Neuroscience letters. 2006;396(1):67-72.

13. Rao SS, Bharucha AE, Chiarioni G, Felt-Bersma R, Knowles C, Malcolm A, et al. Anorectal disorders. Gastroenterology. 2016;150(6):14301442 .

14. Rao SS, Benninga MA, Bharucha AE, Chiarioni G, Di Lorenzo C, Whitehead WE. ANMS-ESNM position paper and consensus guidelines on biofeedback therapy for anorectal disorders. Neurogastroenterology \& Motility. 2015;27(5):594-609.

15. Heymen S, Scarlett Y, Jones K, Ringel Y, Drossman D, Whitehead WE. Randomized controlled trial shows biofeedback to be superior to pelvic floor exercises for fecal incontinence. Diseases of the Colon and Rectum. 2009;52(10):1730-1737. doi: 10.1007/ DCR.0b013e3181b55455. 